\title{
Exposure of e-waste dismantlers from a formal recycling facility in Spain to inhalable organophosphate and halogenated flame retardants
}

\author{
A. Balasch, M. López, C. Reche, M. Viana, T. Moreno, E. Eljarrat \\ Institute of Environmental Assessment and Water Research (IDAEA)-CSIC, Jordi Girona 18-26, 08034, Barcelona, Spain
}

\section{H I G H L I G H T S}

- HFRs and OPEs detected in airborne $\mathrm{PM}_{2.5}$ from an e-waste dismantling facility.

- BDE-209 and TPHP were the predominant HFR and OPE compounds, respectively.

- Human exposure to HFRs and OPEs via $\mathrm{PM}_{2.5}$ inhalation during workday was estimated.

- Workers exposure to HFRs via inhalation was higher than for general population.

- Inhalation non-CR and CR risks were 50 and 25 times lower than threshold risk values.

\section{A R T I C L E I N F O}

Handling Editor: Stefan van Leeuwen

\section{Keywords:}

E-waste

Indoor

Inhalation

Occupational exposure

Organophosphate esters

PBDEs

\section{G R A P H I C A L A B S T R A C T}

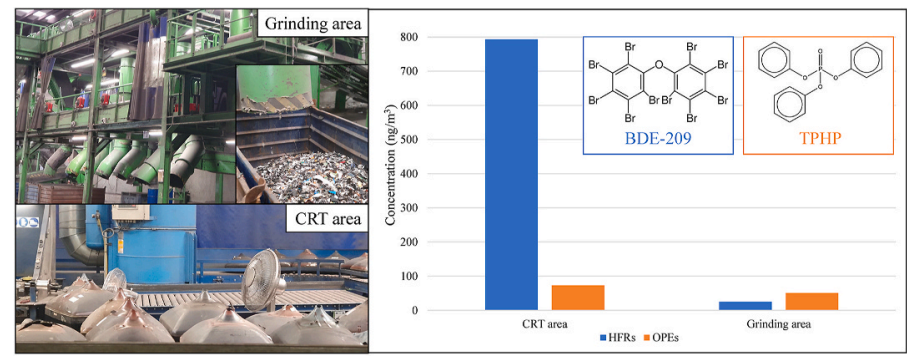




\section{Introduction}

Electronic waste (e-waste) is currently the fastest growing waste on the planet. In 201954 million tonnes were generated in the world, with only $17 \%$ of them being recycled, whereas by 2030 this figure is expected to grow to 75 million tonnes (Forti et al., 2020). E-waste can be made of plastic, ceramics, glass or metal, which are valuable and reusable materials if they are properly recycled. This has resulted in the proliferation of an e-waste recycling industry that has grown annually at an average rate of $4.86 \%$ and calculated to have been worth $\$ 14.5$ billion in 2021 (Sahajwalla and Gaikwad, 2018). In higher income countries recycling is performed in facilities where processes are controlled and regulated, while in low- and middle-income countries manipulation and recycling of e-waste is frequently unregulated, without safety concerns related to the recycling process (Heacock et al., 2016).

Whereas e-waste recycling is necessary and presents numerous advantages for the environment, it can be a hazardous activity as toxic substances such as heavy metals or persistent organic pollutant (POP), flame retardants (FRs) or plasticizers, can be released to the air during the process (Yu et al., 2017; Man et al., 2013; Okeme and Arrandale, 2019).

Flame retardants in the form of polybrominated diphenyl ethers (PBDEs) are commonly found in old electronics devices as halogenated FRs (HFRs) the use of which has been banned by the Stockholm Convention on Persistent Organic Pollutants due to their persistence, bioaccumulation, and toxicity. This ban of PBDEs has resulted in substitution by alternative FRs, including organophosphate ester (OPEs) such as tris(2-chloroethyl) phosphate (TCEP), triphenyl phosphate (TPHP) and tris(2-ethylhexyl) phosphate (TEHP), and other halogenated FRs (HFRs) as chlorinated FRs as dechloranes, or novel brominated FRs (NBFRs), such as bis(2-ethylhexyl) tetrabromophtalate (BEHTBP), decabromodiphenyl ethane (DBDPE), 2-ethyl-hexyl tetrabromobenzoate (EHTBB), hexabromobenzene (HBB), and pentabromoethylbenzene (PBEB) (Gravel et al., 2019; Abbasi et al., 2016; Someya et al., 2016; Matsukami et al., 2015).

Dechlorane plus (DP) is the most commonly used chlorinated FR and is used in polymeric products as computer and television connectors, cable and wire coatings, and plastic roofing materials (Zheng et al., 2010). Regarding DP toxicity, its persistence and bioaccumulation potential have been noted for some time (Sverko et al., 2011). More recently Li et al. (2020) studied the effect of DP on common carp embryos, with their results demonstrating a decrease of hatching rate, increase of mortality rate, a higher probability of deformation and DNA damage. Similarly, Barón et al., 2016 studied the exposure of mussels to DP, finding evidence of genotoxic capacity, inducing DNA damage even at the lowest selected concentrations. The uses of NBFRs are similar to PBDEs, including as a FR additive in for example textiles, plastics, and electrical cable coating, and they have been detected in different environmental matrices such as air, dust, sediments and biota (Xiong et al., 2019). Regarding the toxicity of NBFRs, DBDPE can be hazardous in terms of cardiovascular diseases (Jing et al., 2019) and ЕHTBB and BEHTBP can induce endocrine disruption and 2,3,7,8-tetrachlorodibenzo-p-dioxin-like effects (Li et al., 2017). Organophosphate esters, apart from being applied as FRs, are also used as plasticizers, and they are consequently used across a range of different industries such as plastic, textile, furniture, construction and electronics (Wei et al., 2015). There have been reported toxic effects from some OPEs, for example tris (2-chloroisopropyl) phosphate (TCIPP), Tri- $n$-butyl phosphate (TNBP) and TPHP can all cause endocrine and reproductive disruption, affect nervous system development and are suspected carcinogens (He et al., 2020). Adverse human health impacts have been reported for TCEP, such as hemolytic and reproductive effects, longer estrous cycle length, reduced fertility, and reduced sperm density and motility (Van der Veen and de Boer, 2012).

Workers from e-waste recycling facilities can suffer higher exposures to FRs compared to the general population. This exposure typically arises via three main routes: dermal contact, inhalation and/or nondietary ingestion (Grant et al., 2013). Furthermore, in addition to presenting a potential health risk for the workers, people who live around e-waste dismantling facilities can also be affected (Wang et al., 2011). For example, Lu et al. (2017) found a correlation in e-waste dismantling sites between human exposure to TCEP, TCIPP, TNBP and TPHP and high oxidative stress. Yuan et al. (2008) suggested that PBDEs exposure can interfere with the thyroid hormone system to workers and cause genotoxicity.

The objective of the current study is to assess the exposure and risk by inhalation of workers in a formal e-waste recycling facility located in Spain to 34 FRs from four chemical groups. There are few studies in formal e-waste recycling facilities, which are potential hot spots of FRs in air. Eleven out of the 34 analyzed compounds present noncarcinogenic and/or carcinogenic risk for humans. The risk via inhalation will be evaluated in different working areas from the facility. Three types of e-waste treated in the facility will be analyzed to compare the compounds detected in air with the ones from e-waste, as FRs could be emitted during grinding processes as well as be reintroduced with the circular economy. Exposure to heavy metals and air pollutants $\left(\mathrm{PM}_{2.5}\right.$, black carbon, ultrafine particles), as well as their toxicity, was also assessed in the same facility and is reported elsewhere (López et al., under review).

\section{Materials and methods}

\subsection{Sampling location}

Aerosol sampling was conducted in the largest e-waste dismantling plant in Catalonia (Spain), one of about 50 similar facilities all over Spain. The e-waste at this facility is received from different waste collection points with low recovery potential in Catalonia and the Balearic Islands. It has an output between 1100 and 1300 tonnes per month, which represents around $5 \%$ of the total volume of reused and recycled e-waste in Spain (Statista, 2021). Around 90\% of the e-waste is recovered, with the remaining $10 \%$ being sent to the dump. The facility recovers both small and large appliances, computer and telecommunications equipment, consumer electronics, electric and electronic tools, toys, medical devices, monitoring and control tools and vending machines, separating stainless steel, aluminium, iron, plastics, wires, printed circuit boards and transformers.

The facility is divided into two floors. The ground floor is dedicated to the manual sorting area, the workshop and the grinding area (Fig. 1A), and a loading and unloading area outdoors (Fig. 1B). The indoors of this floor is directly connected with the outdoors via wide openings, ensuring good ventilation. Across this floor all types of e-waste are recycled, except for cathode-ray tube (CRT) TVs which are recycled in an exclusively dedicated area on a higher floor (Fig. 1C). This CRT dedicated area is covered with plastic curtains that greatly reduce its ventilation, and it is connected with stairs to the lower floor and by a door to an office area.

\subsection{Sample collection}

The sampling calendar was divided into two phases. During the first phase, the CRT area was sampled for 3 days in October 2020. In the second phase, the grinding area was sampled for 3 days in November 2020. This makes a total of 6 sampling days, 3 in each area. A sample called "background" was also collected each day for control, but it is important to note that this location was next to the loading and unloading area outdoors (Fig. 1D). Three filters were collected on each sampling day: one for HFR analyses, one for OPEs and the third as background. Sampling time was equal to the shift, being $8 \mathrm{~h}$ in the CRT dismantling area and $6 \mathrm{~h}$ in the grinding area. A scheme of the locations sampled in the facility can be seen in Fig. S1. 


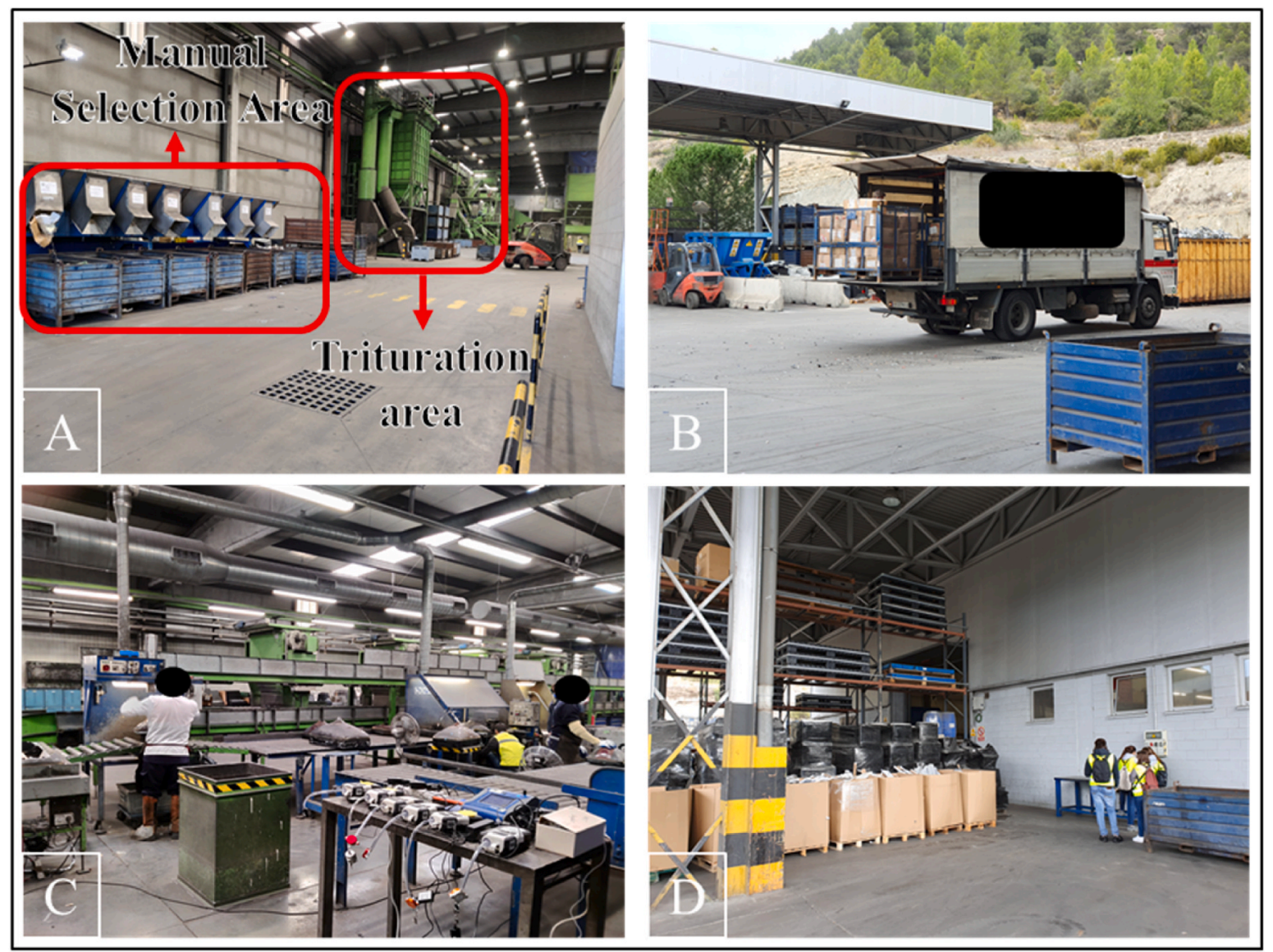

Fig. 1. Sampling areas from the e-waste dismantling facility: manual selection and grinding area (A), loading and unloading area (B), CRT dismantling area (C) and background sample collection area (D).

A total of 18 samples (12 indoor and 6 background samples) of particulate material below $2.5 \mu \mathrm{m}$ in size $\left(\mathrm{PM}_{2.5}\right)$ were collected on quartz microfiber filters (37 mm diameter, PALL) using personal environmental monitors (PEM, SKC) sampling at a flow rate of $0.54 \mathrm{~m}^{3} / \mathrm{h}$. Filters were stored in plastic cases at $-20{ }^{\circ} \mathrm{C}$ before chemical analysis, and possible contamination was corrected by blanks. In addition, three types of the solid e-waste treated in the facility (namely printed circuit boards (PCBs), cables and plastic) were collected after grinding treatment and stored inside a small glass bottle. These additional ground waste samples weighed between 66.3 and $115 \mathrm{~g}$.

\subsection{Standards and reagents}

Information relative to native and labelled standards used in this study are provided in the Supplementary Information. Acetone, dichloromethane and hexane solvents for organic trace analysis were purchased from J.T. Baker (Center Valley, PA, USA). Methanol and water solvent for trace analysis as well as ammonium acetate and formic acid were obtained from Merck (Darmstadt, Germany). Al-N cartridges were obtained by Biotage (Uppsala, Sweden). Hydromatrix was purchased from Agilent Technologies (Santa Clara, CA, USA).

\subsection{Halogenated flame retardant (HFR) analysis}

Filters extraction was performed with a pressurised liquid extraction (PLE) system. Filters were spiked with $20 \mu \mathrm{L}$ of PBDEs internal standards at $0.5 \mathrm{ng} / \mu \mathrm{L}$. After equilibration, samples were loaded into a $22 \mathrm{~mL}$ extraction cell previously loaded with $8 \mathrm{~g}$ of hydromatrix. Dead volume was filled with hydromatrix. The extraction solvent used was hexane: dichloromethane (1:1), at $100{ }^{\circ} \mathrm{C}$ and 1500 psi. Two static extractions of
$10 \mathrm{~min}$ at constant pressure and temperature were developed after an oven heat-up time of $5 \mathrm{~min}$ under these conditions, resulting into an extract about $35 \mathrm{~mL}$. Extracts were concentrated to incipient dryness and redissolved with $2 \mathrm{~mL}$ of hexane. A clean-up was performed with solid phase extraction (SPE) using alumina cartridges (5g). Resulting extracts were concentrated to dryness and reconstituted with toluene for a final volume of $40 \mu \mathrm{L}$ prior to instrument analysis. The detailed instrumental parameters used for HFRs is provided in the Supplementary Information.

\subsection{Organophosphate ester (OPE) analysis}

During the analysis process, the use of plastic material was avoided to reduce any potential contamination, apart from the plastic container used to store the filters. Blank signals were minimized heating nonvolumetric glass material to $340{ }^{\circ} \mathrm{C}$ and rinsing with ethanol and hexane:acetone (1:1) just before use. One blank was included in each batch of samples, and concentration levels of the corresponding samples were corrected.

Filters were spiked with $20 \mu \mathrm{L}$ of internal standard solution $\left(\mathrm{d}_{15^{-}}\right.$ TDCIPP, $\mathrm{d}_{27}$-TNBP, $\mathrm{d}_{12}$-TCEP, $\mathrm{d}_{15^{-}}$TPHP, $\mathrm{d}_{15^{-}}$TEP, $\mathrm{d}_{21^{-}}$-TPP and $\mathrm{d}_{15^{-}}$ TEHP) at $1 \mathrm{ng} / \mu \mathrm{L}$. After equilibration, samples were extracted by placing filters into $40 \mathrm{~mL}$ glass-centrifuge tube and $10 \mathrm{~mL}$ of hexane: acetone (1:1) were added. An ultrasound extraction was performed during $15 \mathrm{~min}$. Extraction was performed twice, and extracts were combined and filtered using glass wool. Finally, the extracts were evaporated to dryness and reconstituted for a final volume of $500 \mu \mathrm{L}$ of methanol before instrumental analysis.

E-waste samples were ground using liquid $\mathrm{N}_{2}$ to homogenize and facilitate the analyses. One gram of e-waste was spiked with $50 \mathrm{ng}$ of 
internal standard solution at $1 \mathrm{ng} / \mu \mathrm{L}$ and $0.5 \mathrm{~g}$ of copper were added. After equilibration, samples were loaded into a $22 \mathrm{~mL}$ extraction cell previously loaded with $8 \mathrm{~g}$ of hydromatrix. Dead volume was filled with hydromatrix. The extraction solvent used was hexane:acetone (1:1), at $50^{\circ} \mathrm{C}$ and $1500 \mathrm{psi}$. Two static extractions of $10 \mathrm{~min}$ at constant pressure and temperature were developed after an oven heat-up time of $5 \mathrm{~min}$ under these conditions, resulting into an extract about $35 \mathrm{~mL}$. Extracts were evaporated to dryness to reconstitute them with $500 \mu \mathrm{L}$ of methanol before the instrumental analysis. The detailed analytical parameters used for OPEs are provided in the Supplementary Information.

\subsection{Quality parameters}

Quality parameters were calculated using QC samples. Two batches of four QC and 1 blank were analyzed following the same procedure from samples, one batch for OPE analysis and the other for HFR analysis. QC samples were spiked with 5 ng of HFR natives or $10 \mathrm{ng}$ of OPE natives and extraction was performed following the same procedure than for regular samples. Previously to final reconstitution, $5 \mathrm{ng}$ of PBDEs IS mixture or $10 \mathrm{ng}$ of OPEs IS mixture were spiked in QC samples and blank. Limits of detection (LODs), limits of quantification (LOQs), recoveries and reproducibility were calculated from QC samples, and they are summarized in Supplementary Information (Table S5). This analytical methodology provides recoveries between 50 and $130 \%$ for OPEs and between 61 and 113\% for HFRs, and with reproducibility always below 15\%. For OPEs, LODs and LOQs ranged between 1.56-87.9 and $5.19-293 \mathrm{pg} / \mathrm{m}^{3}$ respectively, while for HFRs, 0.53-48.1 and $1.78-160 \mathrm{pg} / \mathrm{m}^{3}$ respectively.

In the blanks no HFRs were detected, although TCEP, TCIPP, TDCIPP, TPHP and DCP were present (levels are shown in
Supplementary Information Table S6), with each compound having levels below $17 \%$ of the sample concentration. Signals were subtracted to samples to correct concentrations.

\subsection{Human exposure via inhalation estimates}

In order to assess human exposure to HFRs and OPEs via inhalation, estimated daily intakes $\left(\mathrm{EDI}_{\text {inhalation }}\right)$ were calculated. This parameter is expressed as ng/kg body weight (bw)/day, and is calculated with the following equation: EDI $=$ (Air concentration $\times$ Amount of air inhaled per day $\times$ Exposure time)/Body weight. As all employees were adults, a body weight of $70 \mathrm{~kg}$ and a volume of air inhaled of $19.92 \mathrm{~m}^{3} /$ day were assumed (Maceira et al., 2019). The exposure time corresponded to the shift, that was $6 \mathrm{~h}$ for grinding area and $8 \mathrm{~h}$ for CRT area. For the calculation it was assumed the total absorption in the airways of the inhaled chemicals. In the current study, only exposure via inhalation of $\mathrm{PM}_{2.5}$ during the workday was evaluated. Although this can only be a part of the total inhalation exposure, as gaseous FRs and coarser particulate matter are not considered, it remains of interest, especially as workers from the sampled areas were not using high quality face mas as personal protective equipment (PPE) and fine particles are known to pose the greatest health risk. Due to the COVID-19 pandemic situation workers that had no isolated workplace used cloth or surgical face masks. Note however that for specific activities considered to pose a recognised risk to the workers, the facility provides the suitably appropriate higher quality PPE.

Table 1

OPE and HFR levels (expressed in $\mathrm{ng} / \mathrm{m}^{3}$ ) in $\mathrm{PM}_{2.5}$ samples from e-waste dismantling facility.

\begin{tabular}{|c|c|c|c|c|c|c|c|c|c|}
\hline \multirow[t]{3}{*}{ Compound } & \multirow{2}{*}{\multicolumn{3}{|c|}{ Background }} & \multicolumn{6}{|c|}{ Working Area } \\
\hline & & & & \multicolumn{3}{|c|}{ CRT Area } & \multicolumn{3}{|c|}{ Grinding Area } \\
\hline & 1st day & 2nd day & 3rd day & 1st day & 2nd day & 3rd day & 1st day & 2nd day & 3rd day \\
\hline TCEP & 0.25 & 0.28 & 0.21 & 2.51 & 1.39 & 2.30 & 1.25 & 0.85 & 0.41 \\
\hline TPPO & 0.03 & 0.02 & 0.05 & 0.13 & 0.16 & 0.13 & 0.28 & 0.09 & 0.26 \\
\hline TCIPP & 14.8 & 19.8 & 8.62 & 23.1 & 17.1 & 40.5 & 17.8 & 8.53 & 4.92 \\
\hline TDCIPP & nd & nd & nd & 1.81 & nd & 2.53 & 2.89 & 0.43 & nd \\
\hline ТPHP & 0.26 & nd & 0.71 & 11.4 & 20.0 & 44.3 & 28.0 & 40.9 & 8.32 \\
\hline TNBP & 0.19 & 0.14 & 0.12 & 0.84 & 0.26 & 1.01 & 0.67 & 0.34 & 0.19 \\
\hline DCP & nd & nd & nd & 5.25 & nd & 3.62 & 3.98 & 0.82 & nd \\
\hline 2IPPDPP & nd & nd & nd & 0.34 & nd & 3.57 & 0.23 & nd & nd \\
\hline 4IPPDPP & nd & nd & nd & 0.08 & nd & 0.43 & 0.03 & nd & nd \\
\hline RDP & 0.58 & 0.11 & 0.60 & 4.81 & 6.67 & 8.21 & 20.5 & 6.10 & 1.78 \\
\hline TCP & nd & nd & nd & 0.39 & nd & 0.47 & 1.57 & 0.56 & 0.79 \\
\hline TEHP & 5.09 & 1.45 & 0.11 & 6.07 & 7.15 & 2.46 & 0.36 & 0.19 & 0.10 \\
\hline ¿OPEs & 21.2 & 21.8 & 10.4 & 56.6 & 52.7 & 110 & 77.6 & 58.8 & 16.8 \\
\hline BDE-28 & 0.12 & 0.01 & 0.00 & 0.21 & 0.01 & 0.47 & 0.01 & 0.01 & 0.01 \\
\hline BDE-47 & 3.32 & 0.26 & 0.01 & 4.13 & 0.20 & 4.04 & 0.38 & 0.20 & 0.08 \\
\hline BDE-100 & 0.50 & 0.05 & nd & 0.66 & 0.05 & 0.39 & 0.04 & 0.12 & 0.01 \\
\hline BDE-99 & nd & 0.54 & 0.02 & 7.49 & 0.31 & 4.57 & 0.45 & 0.79 & 0.09 \\
\hline BDE-154 & 0.04 & 0.06 & 0.002 & 0.49 & 0.02 & 1.97 & 0.02 & 0.15 & 0.01 \\
\hline BDE-153 & 0.11 & 0.10 & 0.005 & 1.17 & 0.08 & 9.58 & 0.10 & 0.20 & 0.02 \\
\hline BDE-183 & 0.14 & 0.08 & 0.007 & 0.54 & 0.27 & 41.0 & 0.24 & 0.15 & 0.04 \\
\hline BDE-209 & 32.1 & 4.01 & nd & 62.4 & 8.55 & 1532 & 36.4 & 18.3 & 3.08 \\
\hline इPBDEs & 36.4 & 5.13 & 0.05 & 77 & 9.49 & 1595 & 37.7 & 19.9 & 3.34 \\
\hline ВЕНТВР & nd & nd & 0.37 & 1.58 & nd & 0.20 & 0.01 & nd & nd \\
\hline ЕНTBB & 0.07 & 0.002 & 0.002 & 0.06 & 0.02 & 0.11 & 0.02 & 0.01 & 0.001 \\
\hline HВB & 0.41 & 0.22 & 0.03 & 1.38 & 1.38 & 22.3 & 0.38 & 0.41 & 0.06 \\
\hline PBEB & nd & nd & nd & 0.003 & nd & nd & nd & nd & nd \\
\hline DBDPE & 11.0 & 2.62 & 0.27 & 68.4 & 6.73 & 456 & 3.81 & 8.32 & 1.19 \\
\hline INBFRs & 11.5 & 2.85 & 0.67 & 71 & 8.13 & 479 & 4.22 & 8.74 & 1.25 \\
\hline Dec 602 & 1.12 & nd & nd & nd & nd & 5.6 & nd & nd & nd \\
\hline Dec 603 & 0.45 & nd & nd & nd & nd & nd & nd & nd & nd \\
\hline syn-DP & nd & nd & nd & nd & nd & 33,4 & nd & nd & nd \\
\hline anti-DP & 0,04 & nd & nd & nd & 0,12 & 101 & nd & nd & nd \\
\hline IDec & 1,61 & nd & nd & nd & 0,12 & 140 & nd & nd & nd \\
\hline IHFRs & 49.5 & 7.97 & 0.72 & 149 & 17.7 & 2213 & 41.9 & 28.6 & 4.59 \\
\hline
\end{tabular}




\section{Results and discussion}

\subsection{OPE and HFR levels}

OPE and HFR concentrations determined on $\mathrm{PM}_{2.5}$ filters are summarized in Table 1 . These results include samples from CRT and grinding areas as well as background. OPEs, PBDEs and NBFRs were detected in all samples, but chlorinated FRs were not detected in any sample from the grinding area, and only in some from the CRT area and from the background samples.

Twelve out of sixteen tested OPEs were detected, with B4IPPPP, IDPP, IPPP and THP not being detected in any filter. $\sum$ OPE levels ranged from 10.4 to $110 \mathrm{ng} / \mathrm{m}^{3}$, with the CRT area recording the highest concentrations at a mean value of $73.0 \mathrm{ng} / \mathrm{m}^{3}$, this comparing with a $17.8 \mathrm{ng} / \mathrm{m}^{3}$ mean value for background and $51.0 \mathrm{ng} / \mathrm{m}^{3}$ for the grinding area. The OPEs with highest contributions in both working areas were TPHP and TCIPP, with mean contributions of $42 \%$ and $29 \%$, respectively, followed by RDP (13\%) and DCP (5\%). In contrast, in the background area the main OPE was TCIPP, with a contribution of $81 \%$ of the total concentration (Fig. 2A).

Seventeen out of the eighteen tested HFRs were detected, with only Dechlorane 604 (Dec 604) not being found in any filter. $\sum$ HFRs concentration ranged from 0.72 to $2213 \mathrm{ng} / \mathrm{m}^{3}$, with the CRT area again being the one with highest levels for the three HFR families, registering a mean value of $793 \mathrm{ng} / \mathrm{m}^{3}$ whereas the grinding area presented a mean value of $25 \mathrm{ng} / \mathrm{m}^{3}$ and background was $19.4 \mathrm{ng} / \mathrm{m}^{3}$. In almost all cases the BDE-209 contribution to $\sum$ PBDEs was high, between 78 and $97 \%$, except for one sample from the background area (3rd day) in which BDE-209 was not detected (Fig. 2B). In all three sites PBDE concentrations were higher than those of NBFRs and dechloranes, except for the sample at the background area (3rd day) where NBFR concentration was the highest of the three HFR families. DBDPE followed the same pattern as BDE-209, with NBFR having the highest contribution in almost all samples. Its contribution to $\sum$ NBFRs was from 83 to $96 \%$ except for the sample at the background area (3rd day) where its contribution is only $40 \%$ (Fig. 2C). Dechloranes were only detected in three samples, two from the CRT area (2nd and 3rd days) and one from the background (1st day) with relatively low concentrations compared to the rest of HFRs. Its global contribution to $\sum$ HFRs in these three samples was low, between 0.7 and 6\% (Fig. 2D). The differences were found in contribution profiles from the background area are likely due to the high daily variability of ewaste in this area, as they receive all kind of materials each day, including the e-waste that gets discarded to dump.

In addition to the differences between areas, a high daily variability for OPEs and HFRs was detected. This variability between days was higher for HFRs, with RSD\% values ranging from $80 \%$ to $160 \%$. In the case of OPEs, the values were lower, between $36 \%$ and $61 \%$. The reason of this high daily variability in the same area is probably due to changes in the amount and type of e-waste treated each day.

Total concentration levels of OPEs and HFRs in the three sampled areas are compared in Fig. 3. Mean background levels of OPEs and HFRs were similar (17.8 and $19.4 \mathrm{ng} / \mathrm{m}^{3}$, respectively) whereas in the CRT area HFR levels were over 10 times those of OPE $\left(793\right.$ and $\left.73.0 \mathrm{ng} / \mathrm{m}^{3}\right)$, while in the grinding area OPE levels were two times higher than HFR ( 51.0 and $25.0 \mathrm{ng} / \mathrm{m}^{3}$ ). The higher levels of contamination in the CRT area were due to the high PBDE concentrations, since OPE mean levels did not differ so much between the CRT and grinding area: 73.0 and $51.0 \mathrm{ng} / \mathrm{m}^{3}$, respectively. In contrast, PBDE mean levels in the CRT area $\left(560 \mathrm{ng} / \mathrm{m}^{3}\right)$ were much higher than those in the grinding area $(20.3 \mathrm{ng} /$ $\mathrm{m}^{3}$ ). The higher values from CRT area were probably due to the lower ventilation in this area compared with the grinding area and the difference in the e-waste that is dismantled in each area. $\mathrm{PM}_{2.5}$ levels from the CRT area were higher than those from the ground floor and background (means of 147,78 and $40 \mu \mathrm{g} / \mathrm{m}^{3}$, respectively) (López et al. under review), demonstrating the poorer ventilation. Concentration ratios of $\sum \mathrm{HFR}_{\mathrm{CRT}} / \sum \mathrm{HFR}_{\text {grinding }}$ were much higher than $\sum \mathrm{OPE}_{\mathrm{CRT}} /$

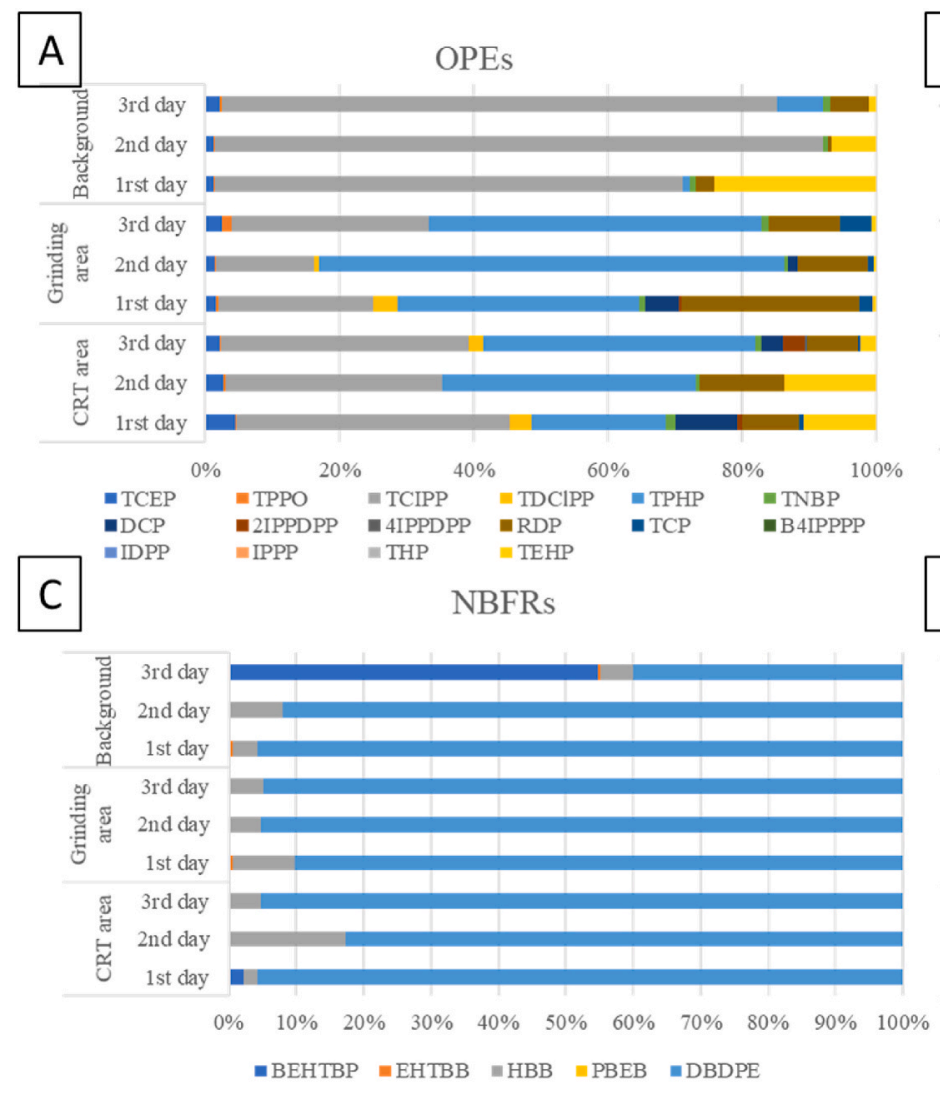

B

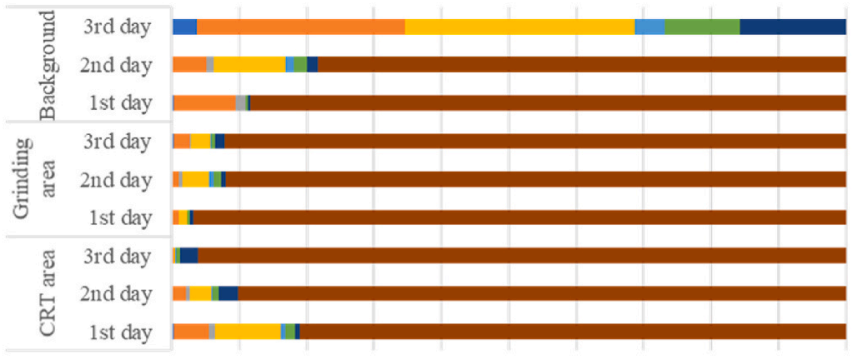

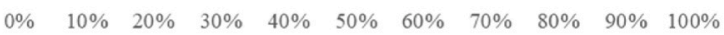
- $\mathrm{BDE} 28=\mathrm{BDE} 47=\mathrm{BDE} 100=\mathrm{BDE} 99=\mathrm{BDE} 154=\mathrm{BDE} 153=\mathrm{BDE} 183=\mathrm{BDE} 209$

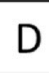

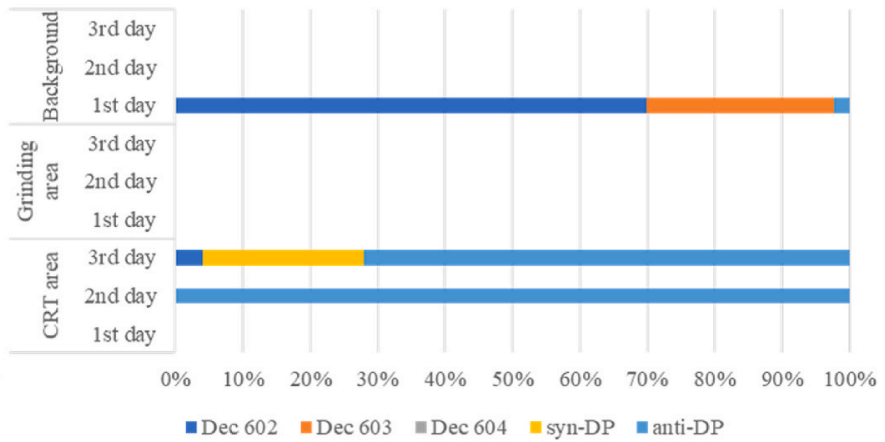

Fig. 2. Percentage contribution of (A) OPEs, (B) PBDEs, (C) NBFRs and (D) Dechloranes, in the different studied areas. 


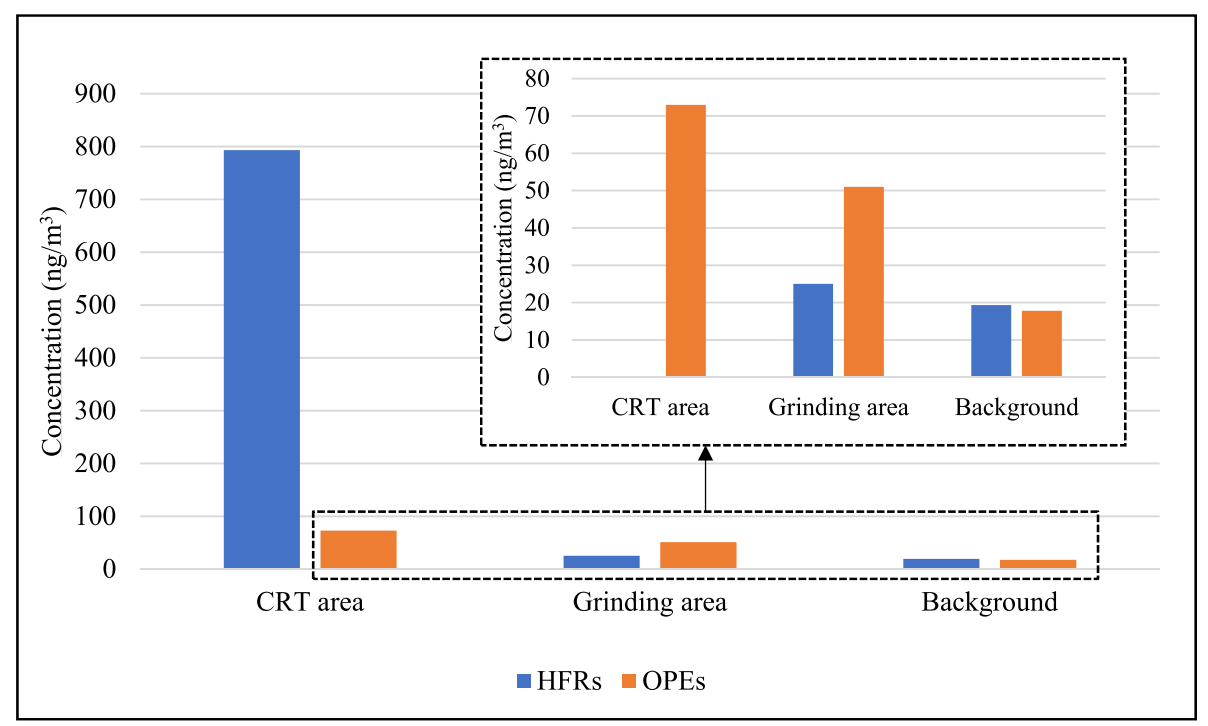

Fig. 3. Comparison between OPE and HFR levels at each sampling area.

$\sum \mathrm{OPE}_{\text {grinding }}$ (31.7 and 1.42, respectively), this huge difference is probably due to PBDEs usage in old TVs produced previously to its ban. This interpretation conforms with the work of Yu et al. (2017) who detected PBDEs (especially BDE-209) with high concentration in PCBs and plastics from CRT TVs, presenting concentrations of $\sum$ PBDEs up to $7.85 \mathrm{mg} / \mathrm{kg}$ in $\mathrm{PBCs}$ and $11.3 \mathrm{mg} / \mathrm{kg}$ in plastics. Thus, we the processing of old TVs as likely responsible for relatively high levels of PBDEs present in airborne $\mathrm{PM}_{2.5}$ at local hotspots within the recycling facility.

\subsection{Comparison with previously published works}

Other studies have conducted analysis of HFRs and OPEs in both formal and informal e-waste facilities and in informal e-waste dismantling regions, although comparison with such data must be carried out with caution as airborne samples were collected using differing sampling techniques and analysing methodologies (Table 2).

OPE levels from the current study are lower than those reported from similar formal Canadian facilities (Nguyen et al., 2019; Gravel et al., 2019). Other regions such as China, where informal e-waste dismantling is more common, presented a wide range of concentrations, being between 1 and 141 times lower than our study (Wang et al., 2018). This difference is probably because sampling was performed in an outdoor area surrounded by e-waste recycling parks, meaning that concentrations will be lower than those from indoor. In China, recycling activities are not usually performed inside a facility, but at different locations within an open area.

Regarding HFRs, levels detected in the CRT area in our study were higher compared with those reported from a Canadian facility (Nguyen et al., 2019), but similar to those obtained from other small and medium facilities from Canada (Gravel et al., 2019). Even if levels in the grinding area from our study were lower than the ones reported from Canadian facilities, they were higher than reported from one e-waste dismantling region from China, where maximum concentration levels were 4 times lower than mean concentration from the grinding area of the current study, and much lower than levels reported from CRT areas and Canadian facilities (Li et al., 2008). Also in China, Liu et al. (2019) studied 6 areas of an e-waste dismantling park and reported a wide range of concentration levels, from the same concentration that we reported in the grinding area $\left(25.0 \mathrm{ng} / \mathrm{m}^{3}\right)$ to more than 5 times our highest reported concentration $\left(2213 \mathrm{ng} / \mathrm{m}^{3}\right)$.

Differences between facilities and informal areas are probably due to ventilation, as informal e-waste dismantling is usually carried out in the street while formal dismantling is done within indoor facilities where pollutant concentrations can build up if air exchange is poor. Thus, in our study differences could be seen between the CRT and grinding areas, with the latter presenting slightly lower levels of OPEs and much lower

Table 2

OPE and HFR levels (expressed in $\mathrm{ng} / \mathrm{m}^{3}$ ) in previous published works in e-waste facilities.

\begin{tabular}{|c|c|c|c|c|c|c|c|c|c|}
\hline \multirow[t]{2}{*}{ Location } & \multirow[t]{2}{*}{ Area } & \multirow[t]{2}{*}{ Sampling } & \multicolumn{3}{|c|}{ OPES } & \multicolumn{3}{|c|}{ HFRs } & \multirow[t]{2}{*}{ Ref. } \\
\hline & & & $\mathrm{n}$ & Range & Mean & $\mathrm{n}$ & Range & Mean & \\
\hline \multirow{2}{*}{$\begin{array}{l}\text { Catalonia, } \\
\text { Spain }\end{array}$} & CRT & \multirow[t]{2}{*}{ Quartz fiber filter } & 16 & $52.7-110$ & 73 & 18 & $17.7-2213$ & 793 & \multirow[t]{2}{*}{ This study } \\
\hline & Grinding & & 16 & $16.8-77.6$ & 51 & 18 & $4.59-41.9$ & 25.0 & \\
\hline \multirow[t]{2}{*}{ Canada } & Central & \multirow[t]{2}{*}{ Quartz fiber filter } & 5 & $71.0-132$ & 102 & 8 & $21.6-185$ & 114.6 & \multirow{2}{*}{$\begin{array}{l}\text { Nguyen et al. } \\
\text { (2019) }\end{array}$} \\
\hline & Workbench & & 5 & $122-1363$ & 359 & 8 & $74.2-561$ & 201 & \\
\hline \multirow[t]{3}{*}{ Canada } & Small facility & \multirow{3}{*}{$\begin{array}{l}\text { XAD-2 sorbent with polyurethane foam } \\
\text { (PUF) plug }\end{array}$} & 3 & $750-1400$ & 980 & 8 & $214-1391$ & 425 & \multirow{3}{*}{$\begin{array}{l}\text { Gravel et al. } \\
\text { (2019) }\end{array}$} \\
\hline & Medium Facility & & 3 & $770-1100$ & 900 & 8 & $784-1221$ & 911 & \\
\hline & Large facility & & 3 & $980-1300$ & 1100 & 8 & $5544-8653$ & 6791 & \\
\hline China & E-waste region & Quartz fiber filter & - & - & - & 9 & $0.15-6.17$ & 1.95 & Li et al. (2008) \\
\hline China & E-waste region & Quartz fiber filter & 9 & $0.775-13.8$ & 4.35 & - & - & - & Wang et al. (2018) \\
\hline China & E-waste dismantling park & Glass fiber filter & - & - & - & 20 & $26.6-11800$ & - & Liu et al. (2019) \\
\hline $\begin{array}{l}\text { Catalonia, } \\
\text { Spain }\end{array}$ & $\begin{array}{l}\text { Indoor (house, office and } \\
\text { school) }\end{array}$ & PUF and glass fiber filter & 20 & $12.5-419$ & 94.6 & 18 & $0.14-2.19$ & 0.806 & $\begin{array}{l}\text { Esplugas et al. } \\
(2022)\end{array}$ \\
\hline $\begin{array}{l}\text { Catalonia, } \\
\text { Spain }\end{array}$ & Outdoor & Quartz fiber filter & - & - & - & 6 & $0.01-0.03$ & 0.02 & Reche et al. (2019) \\
\hline $\begin{array}{l}\text { Across the } \\
\text { globe }\end{array}$ & Outdoor & PFU-PAS & 18 & $0.46-15.1$ & 2.83 & - & - & - & Saini et al. (2020) \\
\hline
\end{tabular}


levels of PBDEs. This difference apart from being due to the different products recycled, is also directly linked with the different ventilation in both areas. The CRT area was almost closed by plastic curtains that barely let air pass through them, while in the grinding area there were wide openings to outdoors facilitating the ventilation.

Finally, we compared our results with those reported in indoor and outdoor environments. Recently, Esplugas et al. (2022) analyzed different FRs in indoor air from homes, offices and schools in Tarragona (Spain). Mean concentration values were 94.6 and $0.806 \mathrm{ng} / \mathrm{m}^{3}$ for OPEs and HFRs, respectively. Comparing these with our results inside the e-waste facility, we concluded that similar values were observed for OPEs (up to $110 \mathrm{ng} / \mathrm{m}^{3}$ ), while HFR levels were considerably higher in our case (up to $2213 \mathrm{ng} / \mathrm{m}^{3}$ ). Regarding outdoor levels, Saini et al. (2020) studied OPEs levels in megacities, where levels were between 0.46 and $15.1 \mathrm{ng} / \mathrm{m}^{3}$, slightly lower than those from the grinding area which presented the lowest levels from the current study. Reche et al. (2019) analyzed HFRs levels in the city of Barcelona (Spain) where and levels were much lower than those from the present study, ranging between 0.01 and $0.03 \mathrm{ng} / \mathrm{m}^{3}$. This suggests that OPEs levels in the e-waste dismantling facility are slightly higher but similar to those from general environment. Concentration of HFRs, specifically PBDEs, reported in our study are higher than the levels from other indoor or outdoor studies, implying that workers have greater exposure compared to the general population.

\subsection{Levels in residues}

OPE levels were analyzed in three different types of e-waste obtained from the facility: printed circuit boards (PCBs), cables and plastic. It is important to note that the e-wastes were only sampled on one of the facility's working days. Therefore, we cannot guarantee the representativeness of these samples, especially taking into account the great variety of e-wastes that arrive at the facility every day. Results are summarized in Table 3. Fourteen out of the sixteen tested OPEs were detected in plastic e-waste, whereas twelve and eleven were detected in PCBs and cables, respectively. Different OPE profiles and levels have been observed in each kind of e-waste. PCBs sample presented the highest $\sum$ OPE concentration (912 $\mu \mathrm{g} / \mathrm{g}$ e-waste), and the main OPEs found were 4IPPDPP (54\%) and 2IPPDPP (26\%), although the contribution of TPHP was also high (17\%). $\sum$ OPE level in plastics was similar to that obtained for PCBs, being $614 \mu \mathrm{g} / \mathrm{g}$ e-waste, but the OPE profile was much different, with DCP (44\%) and RDP (42\%) being the most common compounds in plastic waste. The cables sample recorded has the lowest $\sum$ OPE level, $11.9 \mu \mathrm{g} / \mathrm{g}$ e-waste, that is 51 and 76 times lower than in plastics and PCBs, respectively. In this cables sample, TCIPP was the highest contributing compound (63\%), followed by TCEP (18\%),

Table 3

Concentrations (expressed in $\mathrm{ng} / \mathrm{g}$ ) of OPEs measured in e-waste samples.

\begin{tabular}{llll}
\hline & PCBs & Cables & Plastic \\
\hline TCEP & 15.9 & 2141 & 523 \\
TPPO & 2890 & nd & 8089 \\
TCIPP & 8.04 & 7490 & 3730 \\
TDCIPP & nd & 666 & 1742 \\
TPHP & 151938 & 475 & 33847 \\
TNBP & 5791 & 73.7 & 295.09 \\
DCP & 25350 & 94.6 & 268747 \\
2IPPDPP & 233291 & 107 & 3935 \\
4IPPDPP & 488905 & 76.6 & 16504 \\
RDP & 308 & 751 & 259385 \\
TCP & 1241 & 29.8 & 16359 \\
B4IPPPP & nd & nd & nd \\
IDPP & nd & 27.4 & 101 \\
IPPP & nd & nd & nd \\
THP & 22.2 & nd & 1.42 \\
TEHP & 2375 & nd & 1149 \\
IOPEs & 912135 & 11932 & 614408 \\
\hline
\end{tabular}

TDCIPP (6\%) and RDP (6\%).

The e-waste samples were obtained after grinding, meaning that FRs in e-waste could be released during this process. Theoretically, compounds found in e-waste could be also present in particulate matter sampled next to the grinding area. Comparing our OPE results in e-waste with $\mathrm{PM}_{2.5}$ measured from the grinding area, we found some evidence for this. For instance, the TPHP contribution to OPE contamination in $\mathrm{PM}_{2.5}$ was $52 \%$; this OPE also being present in e-waste at percentage contributions of 17,4 and $6 \%$ in PCBs, cables and plastic, respectively. TCIPP, which is the second most abundant OPE recorded from $\mathrm{PM}_{2.5}$ (22\%), was the most contributing OPE in cables (63\%); and RDP, which is the third compound with higher contribution in $\mathrm{PM}_{2.5}(16 \%)$, was one of the predominant compounds in the plastic sample (42\%), as well as being detected in the cables sample (6\%).

However, not all the compounds with high concentrations in e-waste presented high levels in the $\mathrm{PM}_{2.5}$. This is the case for 2IPPDPP and 4IPPDPP which despite contributing 26 and 54\% to the OPE concentration in PCBs sample, were very low $(<0.5 \%)$ in $\mathrm{PM}_{2.5}$. The same situation was observed for TCEP: their contribution in the cables sample was $18 \%$, falling to $2 \%$ in $\mathrm{PM}_{2.5}$. Finally, despite the fact that DCP is the most abundant OPE in the plastic sample (44\%), its contribution in $\mathrm{PM}_{2.5}$ was also very low (3\%). These differences may be due to emission of some OPE compounds as coarser particles, in a larger size fraction than $\mathrm{PM}_{2.5}$. It would be necessary to carry out a more exhaustive study in order to determine the reason for these differences between the contributions of the different OPEs in e-waste and in $\mathrm{PM}_{2.5}$ samples by collecting a greater number of samples and on different days, given the likely variations in e-waste materials dealt with by the recycling facility.

The high OPE levels in e-waste samples highlight the risk of recycling these materials, since their re-circulation leads to the re-introduction of toxic compounds into the environment. It is clearly advisable to evaluate levels of contaminants in these types of materials before deciding on their reuse. In addition to the OPEs and HFRs analyzed in this work, this is also a problem for heavy metals and air pollutants (ultrafine particles, black carbon, etc.), as discussed by López et al. (under review).

\subsection{Human exposure assessment to HFRs and OPEs via inhalation}

Human exposure to FRs via airborne $\mathrm{PM}_{2.5}$ inhalation during work shifts from e-waste recycling facilities employees was assessed. It must be indicated that other sources of exposure, as dust ingestion and dermal contact, are not considered in this study. This inhalation exposure assessment focuses on $\mathrm{PM}_{2.5}$, as a well-established stronger risk factor than coarser particles (Samoli et al., 2008; Beelen et al., 2008; Krewski et al., 2009). Nonetheless, it must be noted that certain underestimation of the results due to the lack of data on coarser particles and on the gas phase can not be discarded.

$\mathrm{EDI}_{\text {inhalation }}$ values were calculated, and obtained results are summarized in Table S7. Mean values from the 3 sampling days were calculated and applied for the calculation. As shown, $\mathrm{EDI}_{\text {inhalation values }}$ from workers in the CRT area are higher than those from the grinding area. This is mainly due to the difference between mean concentrations of OPE and HFR in both areas, with concentrations in the CRT area around two times and more than ten times higher than those of the grinding area, respectively. Also note that the exposure time was different, as the shift lasts for $8 \mathrm{~h}$ in the CRT area and $6 \mathrm{~h}$ for the grinding one. This difference is presumably influenced by the lower ventilation in the CRT area when compared to the grinding area.

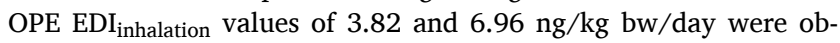
tained for the grinding and CRT area, respectively. These values were similar to those reported by He et al. (2018), who evaluated the OPE $\mathrm{EDI}_{\text {inhalation }}$ for the Australian population, assuming that we spend the $88 \%$ of time in indoor environments, that is $21.12 \mathrm{~h}$. They reported an OPE $\mathrm{EDI}_{\text {inhalation }}$ of $7.9 \mathrm{ng} / \mathrm{kg} \mathrm{bw} /$ day. However, if we refer our values and those reported in the Australian study to the same exposure time, i.e. $8 \mathrm{~h}$, our values range between 5.09 and $6.96 \mathrm{ng} / \mathrm{kg}$ bw/day, in contrast 
with $2.99 \mathrm{ng} / \mathrm{kg}$ bw/day for the Australian study, with OPE EDI $_{\text {inhalation }}$ values from e-waste facility being (as would be expected) higher than those calculated for indoor inhalation of the Australian population.

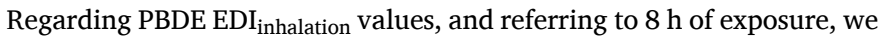
found 1.92 and $53.2 \mathrm{ng} / \mathrm{kg}$ bw/day for the grinding and CRT area, respectively. These values were from 480 to 13300 times higher than the HFR exposure reported for the Australian population $(0.004 \mathrm{ng} / \mathrm{kg}$ bw/day). Kakimoto et al. (2014) reported the inhalation exposure to PBDEs in Osaka, Japan, with an estimated value of $0.0034 \mathrm{ng} / \mathrm{kg}$ bw/day, these being similar to data calculated for the Australian population, and much lower than that reported in the current study. Sha et al. (2018) reported levels of $\mathrm{EDI}_{\text {inhalation }}$ in homes and offices for brominated FRs (BFRs), including PBDEs, and OPEs, ranging between 6.7 and $50 \mathrm{pg} / \mathrm{kg} \mathrm{bw} /$ day for BFRs and from 44 to $220 \mathrm{pg} / \mathrm{kg}$ bw/day for OPEs. In both cases, reported levels were lower compared with the current study. Thus, we observe that OPE and HFR exposure of e-waste dismantlers in our study was higher than that of the general population, especially in the case of PBDEs. The differences are not so great for OPEs, although levels are slightly superior than those reported from Australia and clearly higher than the ones reported by Sha et al. (2018) in homes and offices. Therefore, e-waste dismantling workers should be considered as a risk group, and it is important to minimize their exposure to these toxic compounds, especially HFRs, through the use of PPE as face masks to reduce particle inhalation.

USEPA, 2019 updated the oral reference dose (RfD) and oral cancer slope factors (SFO) of some OPEs and HFRs (Table S7). Non-carcinogenic (non-CR) as well as carcinogenic (CR) risks of OPE and HFR exposure via airborne particle inhalation during the workday were estimated. This was based on RfDs instead of inhalation reference concentrations (RfCs), which would be the correct approximation, since RfCs have not been developed from USEPA for OPEs and HFRs as there is not enough information from studies in humans or animals. Table 4 shows the obtained non-CR and CR risks assuming that all of the inhaled compounds are completely absorbed into the blood, this being a conservative approach.

In order to calculate non-CR risk, $\mathrm{EDI}_{\text {inhalation }}$ values were divided by the corresponding RfD. If the obtained value was higher than one, a potential non-CR risk to humans might occur. The obtained results showed that daily exposure by inhalation to OPEs and HFRs does not suppose a non-CR risk by itself, as no individual non-CR risk was higher than one, including using the sum of all non-CR risk for each area. Highest values were obtained from the CRT area, with $\sum$ OPEs having a risk of $3.07 \times 10^{-4}$ and $\sum$ HFRs $1.91 \times 10^{-2}$. The highest risk values were found at the CRT area, basically due to the presence of HFRs, in particular, of PBDEs.

Table 4

Non-carcinogenic and carcinogenic risk of exposure to OPEs and HFRs by $\mathrm{PM}_{2.5}$ inhalation during the time expended working.

\begin{tabular}{|c|c|c|c|c|}
\hline \multirow[t]{2}{*}{ Compound } & \multicolumn{2}{|c|}{ Risk (CRT area) } & \multicolumn{2}{|c|}{ Risk (Grinding area) } \\
\hline & Non-CR & CR Risk & Non-CR & CR Risk \\
\hline TNBP & $6.66 \times 10^{-6}$ & $5.99 \times 10^{-10}$ & $2.86 \times 10^{-6}$ & $2.57 \times 10^{-10}$ \\
\hline TCEP & $2.80 \times 10^{-5}$ & $3.92 \times 10^{-9}$ & $8.48 \times 10^{-6}$ & $1.19 \times 10^{-9}$ \\
\hline TEHP & $4.96 \times 10^{-6}$ & $1.59 \times 10^{-9}$ & $1.54 \times 10^{-7}$ & $4.92 \times 10^{-11}$ \\
\hline TCIPP & $2.55 \times 10^{-4}$ & - & $7.41 \times 10^{-5}$ & - \\
\hline TDCIPP & $1.03 \times 10^{-5}$ & - & $5.90 \times 10^{-6}$ & - \\
\hline TMCP & $2.53 \times 10^{-6}$ & - & $4.33 \times 10^{-6}$ & - \\
\hline ¿OPEs & $3.07 \times 10^{-4}$ & $6.11 \times 10^{-9}$ & $9.58 \times 10^{-5}$ & $1.49 \times 10^{-9}$ \\
\hline BDE-47 & $2.06 \times 10^{-3}$ & - & $1.54 \times 10^{-4}$ & \\
\hline BDE-99 & $3.91 \times 10^{-3}$ & - & $3.18 \times 10^{-4}$ & \\
\hline BDE-153 & $1.71 \times 10^{-3}$ & - & $3.71 \times 10^{-5}$ & \\
\hline BDE-209 & $7.24 \times 10^{-3}$ & $3.55 \times 10^{-8}$ & $1.96 \times 10^{-4}$ & $9.59 \times 10^{-10}$ \\
\hline ¿PBDEs & $1.49 \times 10^{-2}$ & $3.55 \times 10^{-8}$ & $7.04 \times 10^{-4}$ & $9.59 \times 10^{-10}$ \\
\hline HBB & $4.18 \times 10^{-3}$ & - & $1.01 \times 10^{-5}$ & - \\
\hline$\Sigma$ NBFRs & $4.18 \times 10^{-3}$ & - & $1.01 \times 10^{-5}$ & - \\
\hline$\Sigma$ HFRs & $1.91 \times 10^{-2}$ & $3.55 \times 10^{-8}$ & $7.15 \times 10^{-4}$ & $9.59 \times 10^{-10}$ \\
\hline$\Sigma$ FRs & $1.94 \times 10^{-2}$ & $4.16 \times 10^{-8}$ & $8.11 \times 10^{-4}$ & $2.45 \times 10^{-9}$ \\
\hline
\end{tabular}

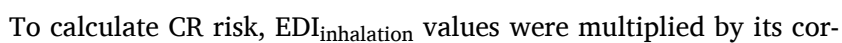
responding SFO. It was considered an acceptable level of risk one cancer incidence case per million people (USEPA, 2019). That means that CR risk values higher than $1 \times 10^{-6}$ exceed safety threshold, which supposes potential adverse effects. The obtained results were much lower than $1 \times 10^{-6}$, indicating that there is no CR risk for dismantling workers. Once again, the highest CR risk was obtained for the CRT area, with a significant contribution from BDE-209.

Focusing on the most contaminated area (CRT area), the non-CR risk was 50 times lower than 1 , and the CR risk was 25 times lower than $1 \times$ $10^{-6}$. Even if there is apparently non-CR and CR risks from the exposure during workday, the exposition to OPEs and HFRs might occur in other indoor environments, and by other routes, such as dietary intake and dust ingestion. The sum of all these sources could bring the values closer to the safety threshold. Applying in the recycling facility immediate short term measures, such as the use of PPE, combined with mediumlong term plans to limit the levels of these contaminants in the original electronic products, would reduce the contribution of OPE and HFR exposure for workers in this environment.

\section{Conclusions}

Concentration levels of 16 OPEs and 18 HFRs were measured in $\mathrm{PM}_{2.5}$ from an e-waste dismantling facility. OPEs and HFRs were detected in all analyzed samples, with OPE levels between 16.8 and 110 $\mathrm{ng} / \mathrm{m}^{3}$ and HFR levels between 0.72 and $2213 \mathrm{ng} / \mathrm{m}^{3}$. The highest contributing compounds to total OPE levels were TPHP and TCIPP, whereas BDE-209 and DBDPE were the most contributing compounds to total HFR concentrations. Differences were observed between the two studied areas, with the CRT area being the one with the highest concentrations, basically due to the highest levels of HFRs, associated with the lower ventilation (air exchange rates) and the e-waste being processed. The grinding area presented lower levels, although still higher than those in the outdoor background area. The high levels of PBDEs, especially of BDE-209, detected in the CRT area might be a concern because, even if its usage has been banned since 2008 in the EU (ECD, 2009), activities as e-waste recycling result in its re-release into the environment. Thus, the reduction in environmental levels of BDE-209 could be slowed down by this new source. To minimize toxicological effects, e-waste dismantling should be performed in places where the impact to environment and human health is as low as possible, especially where these activities are carried out in areas without control, as is the case in some developing countries.

The most abundant OPEs detected in $\mathrm{PM}_{2.5}$ were also detected in the e-waste treated in this facility (ground from cables, printed circuit boards and plastic) at high concentration levels. These findings also highlight the risk of environmental contamination due to the recycling of these materials. It would be advisable that FR levels in e-waste were evaluated before proceeding to its re-use.

Regarding human health, exposure to FRs by inhalation of $\mathrm{PM}_{2.5}$ during the workday in the facility was estimated, with $\mathrm{EDI}_{\text {inhalation }}$ values up to 6.96 and $53.2 \mathrm{ng} / \mathrm{kg}$ bw/day for OPEs and HFRs, respectively. Based on these values non-CR and CR risks were assessed, resulting in levels always below the risk threshold. However, it is important to note that the possibility of reaching the relevant thresholds if other exposure routes, such as dietary intake and dust ingestion, are taken into consideration. As the contribution of OPE and HFR exposure during the work in the recycling facility is high, we recommended taking precautionary measures such as the use of PPE to reduce exposure to pollutants in this type of occupational setting.

\section{Author statement}

Aleix Balasch: formal analysis; data treatment; methodology; validation; writing of the original manuscript draft and revision of the manuscript. Maria López: sampling and revision of the manuscript. 
Cristina Reche: conceptualization and coordination of the study; supervision; sampling, revision of the manuscript; resources and funding acquisition. Mar Viana: conceptualization and coordination of the study; supervision; sampling and revision of the manuscript. Teresa Moreno: revision of the manuscript. Ethel Eljarrat: conceptualization and coordination of the study; supervision; methodology; validation; writing of the original manuscript draft and revision of the manuscript; resources and funding acquisition. All authors have read and approved the final article.

\section{Declaration of competing interest}

The authors declare that they have no known competing financial interests or personal relationships that could have appeared to influence the work reported in this paper.

\section{Acknowledgements}

This study was supported by the Grant CEX 2018-000794-S funded by MCIN/AEI/10.13039/501100011033 through the Project "Evaluación de patrones de exposición personal multi-vía a contaminantes clásicos y emergentes", by the Spanish Ministry of Science and Innovation (Project EXPOPLAS PID 2019-110576RB-I00, and RTI2018098095-B-C21), and by the Generalitat de Catalunya - Consolidated Research Group Water and Soil Quality Unit 2017 SGR 1404. A. Balasch thank his fellowship PRE 2020-091979. The authors would like to thank the plant manager and operators of the dismantling facility that helped during the sampling campaign. Biotage is acknowledged for providing SPE cartridges.

\section{Appendix A. Supplementary data}

Supplementary data to this article can be found online at https://doi. org/10.1016/j.chemosphere.2022.133775.

\section{References}

Abbasi, G., Saini, A., Goosey, E., Diamond, M.L., 2016. Product screening for sources of halogenated flame retardants in Canadian house and office dust. Sci. Total Environ. 545-546, 299-307. https://doi.org/10.1016/j.scitotenv.2015.12.028.

Barón, E., Dissanayake, A., Vilà-Cano, J., Crowther, C., Readman, J.W., Jha, A.N., Eljarrat, E., Barceló, D., 2016. Evaluation of the genotoxic and physiological effects of decabromodiphenyl ether (BDE-209) and dechlorane plus (DP) flame retardants in marine mussels (Mytilus galloprovincialis). Environ. Sci. Technol. 50, 2700-2708. https://doi.org/10.1021/acs.est.5b05814.

Beelen, R., Hoek, G., van den Brandt, P.A., Goldbohm, R.A., Fischer, P., Schouten, L.J., Jerrett, M., Hughes, E., Armstrong, B., Brunekreef, B., 2008. Long-term effects of traffic-related air pollution on mortality in a Dutch cohort (NLCS-AIR study). Environ. Health Perspect. 116, 196-202. https://doi.org/10.1289/ehp.10767.

ECD, 2009. Commission decision 2005/717/EC - Exemption of DecaBDE from teh prohibition on use, C116 (May 9, 2008). Off. J. Eur. Union.

Esplugas, R., Rovira, J., Mari, M., Fernández-Arribas, J., Eljarrat, E., Domingo, J.L., Schuhmacher, M., 2022. Emerging and legacy flame retardants in indoor air and dust samples of Tarragona Province (Catalonia, Spain). Sci. Total Environ. 806 https:// doi.org/10.1016/j.scitotenv.2021.150494.

Forti, V., Baldé, C.P., Kuehr, R., Bel, G., 2020. The Global E-Waste Monitor 2020.

Grant, K., Goldizen, F.C., Sly, P.D., Brune, M.N., Neira, M., van den Berg, M., Norman, R. E., 2013. Health consequences of exposure to e-waste: a systematic review. Lanc. Glob. Health 1, e350-e361. https://doi.org/10.1016/S2214-109X(13)70101-3.

Gravel, S., Lavoué, J., Bakhiyi, B., Diamond, M.L., Jantunen, L.M., Lavoie, J., Roberge, B., Verner, M.A., Zayed, J., Labrèche, F., 2019. Halogenated flame retardants and organophosphate esters in the air of electronic waste recycling facilities: evidence of high concentrations and multiple exposures. Environ. Int. 128, 244-253. https://doi.org/10.1016/j.envint.2019.04.027.

He, C., Lin, C.Y., Mueller, J.F., 2020. Organophosphate Flame Retardants in the Environment: Source, Occurrence, and Human Exposure, first ed. Elsevier B.V. https://doi.org/10.1016/bs.coac.2019.10.008. Comprehensive Analytical Chemistry.

He, C., Wang, X., Thai, P., Baduel, C., Gallen, C., Banks, A., Bainton, P., English, K., Mueller, J.F., 2018. Organophosphate and brominated flame retardants in Australian indoor environments: levels, sources, and preliminary assessment of human exposure. Environ. Pollut. 235, 670-679. https://doi.org/10.1016/j. envpol.2017.12.017.

Heacock, M., Kelly, C.B., Asante, K.A., Birnbaum, L.S., Bergman, Å.L., Bruné, M.N., Buka, I., Carpenter, D.O., Chen, A., Huo, X., Kamel, M., Landrigan, P.J., Magalini, F.,
Diaz-Barriga, F., Neira, M., Omar, M., Pascale, A., Ruchirawat, M., Sly, L., Sly, P.D., van den Berg, M., Suk, W.A., 2016. E-waste and harm to vulnerable populations: a growing global problem. Environ. Health Perspect. 124, 550-555. https://doi.org/ 10.1289/ehp.1509699.

Jing, L., Sun, Y., Wang, Y., Liang, B., Chen, T., Zheng, D., Zhao, X., Zhou, X., Sun, Z., Shi, Z., 2019. Cardiovascular toxicity of decabrominated diphenyl ethers (BDE-209) and decabromodiphenyl ethane (DBDPE) in rats. Chemosphere 223, 675-685. https://doi.org/10.1016/j.chemosphere.2019.02.115.

Kakimoto, K., Nagayoshi, H., Takagi, S., Akutsu, K., Konishi, Y., Kajimura, K., Hayakawa, K., Toriba, A., 2014. Inhalation and dietary exposure to Dechlorane Plus and polybrominated diphenyl ethers in Osaka, Japan. Ecotoxicol. Environ. Saf. 99, 69-73. https://doi.org/10.1016/j.ecoenv.2013.10.023.

Krewski, D., Jerrett, M., Burnett, R.T., Ma, R., Hughes, E., Shi, Y., Turner, M.C., Pope, C. A., Thurston, G., Calle, E.E., Thun, M.J., Beckerman, B., DeLuca, P., Finkelstein, N., Ito, K., Moore, D.K., Newbold, K.B., Ramsay, T., Ross, Z., Shin, H., Tempalski, B., 2009. Extended follow-up and spatial analysis of the American Cancer Society study linking particulate air pollution and mortality. Res. Rep. Health Eff. Inst.

Li, B., Chen, J., Du, Q., Wang, B., Qu, Y., Chang, Z., 2020. Toxic effects of dechlorane plus on the common carp (Cyprinus carpio) embryonic development. Chemosphere 249, 126481. https://doi.org/10.1016/j.chemosphere.2020.126481.

Li, W.L., Ma, W.L., Zhang, Z.F., Liu, L.Y., Song, W.W., Jia, H.L., Ding, Y.S., Nakata, H., Minh, N.H., Sinha, R.K., Moon, H.B., Kannan, K., Sverko, E., Li, Y.F., 2017. Occurrence and source effect of novel brominated flame retardants (NBFRs) in soils from five asian countries and their relationship with PBDEs. Environ. Sci. Technol. 51, 11126-11135. https://doi.org/10.1021/acs.est.7b03207.

Li, Y.M., Jiang, G. Bin, Wang, Y.W., Wang, P., Zhang, Q.H., 2008. Concentrations, profiles and gas-particle partitioning of PCDD/Fs, PCBs and PBDEs in the ambient air of an E-waste dismantling area, southeast China. Chin. Sci. Bull. 53, 521-528. https://doi.org/10.1007/s11434-008-0125-8.

Liu, R., Ma, S., Li, G., Yu, Y., An, T., 2019. Comparing pollution patterns and human exposure to atmospheric PBDEs and PCBs emitted from different e-waste dismantling processes. J. Hazard Mater. 369, 142-149. https://doi.org/10.1016/j jhazmat.2019.02.029.

López, M., Reche, C., Pérez-Albaladejo, E., Porte, C., Balasch, A., Monfort, E., Eljarrat, E., Viana, M., n.d. E-waste dismantling as a source of personal exposure and environmental release of fine and ultrafine particles. Sci. Total Environ.

Lu, S.Y., Li, Y.X., Zhang, T., Cai, D., Ruan, J.J., Huang, M.Z., Wang, L., Zhang, J.Q. Qiu, R.L., 2017. Effect of E-waste recycling on urinary metabolites of organophosphate flame retardants and plasticizers and their association with oxidative stress. Environ. Sci. Technol. 51, 2427-2437. https://doi.org/10.1021/acs. est.6b05462.

Maceira, A., Borrull, F., Marcé, R.M., 2019. Occurrence of plastic additives in outdoor air particulate matters from two industrial parks of Tarragona, Spain: human inhalation intake risk assessment. J. Hazard Mater. 373, 649-659. https://doi.org/10.1016/j jhazmat.2019.04.014.

Man, M., Naidu, R., Wong, M.H., 2013. Persistent toxic substances released from uncontrolled e-waste recycling and actions for the future. Sci. Total Environ. 463-464, 1133-1137. https://doi.org/10.1016/j.scitotenv.2012.07.017.

Matsukami, H., Tue, N.M., Suzuki, G., Someya, M., Tuyen, L.H., Viet, P.H., Takahashi, S., Tanabe, S., Takigami, H., 2015. Flame retardant emission from e-waste recycling operation in northern Vietnam: environmental occurrence of emerging organophosphorus esters used as alternatives for PBDEs. Sci. Total Environ. 514, 492-499. https://doi.org/10.1016/j.scitotenv.2015.02.008.

Nguyen, L.V., Diamond, M.L., Venier, M., Stubbings, W.A., Romanak, K., Bajard, L., Melymuk, L., Jantunen, L.M., Arrandale, V.H., 2019. Exposure of Canadian electronic waste dismantlers to flame retardants. Environ. Int. 129, 95-104. https:// doi.org/10.1016/j.envint.2019.04.056.

Okeme, J.O., Arrandale, V.H., 2019. Electronic waste recycling: occupational exposures and work-related health effects. Curr. Environ. Heal. Rep. 6, 256-268. https://doi. org/10.1007/s40572-019-00255-3.

Reche, C., Viana, M., Querol, X., Corcellas, C., Barceló, D., Eljarrat, E., 2019. Particlephase concentrations and sources of legacy and novel flame retardants in outdoor and indoor environments across Spain. Sci. Total Environ. 649, 1541-1552. https:// doi.org/10.1016/j.scitotenv.2018.08.408.

Sahajwalla, V., Gaikwad, V., 2018. The present and future of e-waste plastics recycling. Curr. Opin. Green Sustain. Chem. 13, 102-107. https://doi.org/10.1016/j. cogsc. 2018.06.006.

Saini, A., Harner, T., Chinnadhurai, S., Schuster, J.K., Yates, A., Sweetman, A., Aristizabal-Zuluaga, B.H., Jiménez, B., Manzano, C.A., Gaga, E.O., Stevenson, G., Falandysz, J., Ma, J., Miglioranza, K.S.B., Kannan, K., Tominaga, M., Jariyasopit, N., Rojas, N.Y., Amador-Muñoz, O., Sinha, R., Alani, R., Suresh, R., Nishino, T., Shoeib, T., 2020. GAPS-megacities: a new global platform for investigating persistent organic pollutants and chemicals of emerging concern in urban air. Environ. Pollut. 267 https://doi.org/10.1016/j.envpol.2020.115416.

Samoli, E., Peng, R., Ramsay, T., Pipikou, M., Touloumi, G., Dominici, F., Burnett, R., Cohen, A., Krewski, D., Samet, J., Katsouyanni, K., 2008. Acute effects of ambient particulate matter on mortality in Europe and North America: results from the APHENA study. Environ. Health Perspect. 116, 1480-1486. https://doi.org/ 10.1289/ehp.11345.

Sha, B., Dahlberg, A.K., Wiberg, K., Ahrens, L., 2018. Fluorotelomer alcohols (FTOHs), brominated flame retardants (BFRs), organophosphorus flame retardants (OPFRs) and cyclic volatile methylsiloxanes (cVMSs) in indoor air from occupational and home environments. Environ. Pollut. 241, 319-330. https://doi.org/10.1016/j. envpol.2018.04.032.

Someya, M., Suzuki, G., Ionas, A.C., Tue, N.M., Xu, F., Matsukami, H., Covaci, A., Tuyen, L.H., Viet, P.H., Takahashi, S., Tanabe, S., Takigami, H., 2016. Occurrence of 
emerging flame retardants from e-waste recycling activities in the northern part of Vietnam. Emerg. Contam. 2, 58-65. https://doi.org/10.1016/j.emcon.2015.10.002.

Statista, 2021. Volumen de residuos de aparatos eléctricos y electrónicos (RAEE) reutilizados y reciclados en España de 2007 a 2018 [WWW Document]. URL, 1.14.22. https://es.statista.com/estadisticas/619794/cifra-de-basura-electroni ca-reutilizada-y-reciclada-en-espana/.

Sverko, E., Tomy, G.T., Reiner, E.J., Li, Y.F., McCarry, B.E., Arnot, J.A., Law, R.J., Hites, R.A., 2011. Dechlorane plus and related compounds in the environment: a review. Environ. Sci. Technol. 45, 5088-5098. https://doi.org/10.1021/es2003028.

USEPA, 2019. Regional Screening Levels (RSLs) [WWW Document]. URL. https://www. epa.gov/risk/regional-screening-levels-rsls-generic-tables.

Van der Veen, I., de Boer, J., 2012. Phosphorus flame retardants: properties, production, environmental occurrence, toxicity and analysis. Chemosphere 88, 1119-1153. https://doi.org/10.1016/j.chemosphere.2012.03.067.

Wang, H., Han, M., Yang, S., Chen, Y., Liu, Q., Ke, S., 2011. Urinary heavy metal levels and relevant factors among people exposed to e-waste dismantling. Environ. Int. 37, 80-85. https://doi.org/10.1016/j.envint.2010.07.005.

Wang, Tao, Ding, N., Wang, Ting, Chen, S.J., Luo, X.J., Mai, B.X., 2018 Organophosphorus esters (OPEs) in PM2.5 in urban and e-waste recycling regions in southern China: concentrations, sources, and emissions. Environ. Res. 167, 437-444. https://doi.org/10.1016/j.envres.2018.08.015.
Wei, G.L., Li, D.Q., Zhuo, M.N., Liao, Y.S., Xie, Z.Y., Guo, T.L., Li, J.J., Zhang, S.Y., Liang, Z.Q., 2015. Organophosphorus flame retardants and plasticizers: sources, occurrence, toxicity and human exposure. Environ. Pollut. 196, 29-46. https://doi. org/10.1016/j.envpol.2014.09.012.

Xiong, P., Yan, X., Zhu, Q., Qu, G., Shi, J., Liao, C., Jiang, G., 2019. A review of environmental occurrence, fate, and toxicity of novel brominated flame retardants. Environ. Sci. Technol. 53, 13551-13569. https://doi.org/10.1021/acs.est.9b03159.

Yu, D., Duan, H., Song, Q., Liu, Y., Li, Y., Li, J., Shen, W., Luo, J., Wang, J., 2017. Characterization of brominated flame retardants from e-waste components in China. Waste Manag. 68, 498-507. https://doi.org/10.1016/j.wasman.2017.07.033.

Yuan, J., Chen, L., Chen, D., Guo, H., Bi, X., Ju, Y., Jiang, P., Shi, J., Yu, Z., Yang, J., Li, L., Jiang, Q., Sheng, G., Fu, J., Wu, T., Chen, X., 2008. Elevated serum polybrominated diphenyl ethers and thyroid-stimulating hormone associated with lymphocytic micronuclei in Chinese workers from an e-waste dismantling site. Environ. Sci. Technol. 42, 2195-2200. https://doi.org/10.1021/es702295f.

Zheng, J., Wang, J., Luo, X.J., Tian, M., He, L.Y., Yuan, J.G., Mai, B.X., Yang, Z.Y., 2010. Dechlorane plus in human hair from an e-waste recycling area in South China: comparison with dust. Environ. Sci. Technol. 44, 9298-9303. https://doi.org/ 10.1021/es103105x. 